\title{
Mental health strategy needs national buy-in
}

$\mathrm{C}$ anada's proposed mental health strategy will require a major grassroots advocacy campaign to ensure that it is adopted across all segments of society, says Michael Kirby, the first chair of the Mental Health Commission of Canada.

"The strategy is a superb product," says Kirby, a former Liberal senator who led a Senate report into mental health that sparked the creation of the commission. "But to sell it, to get it adopted, is going to require a strong marketing effort."

The commission rolled out a national mental health strategy, Changing Directions Changing Lives, at a news conference in Ottawa, Ontario, May 8. The 152-page document contains 109 recommendations about how to improve the mental health system and change attitudes that have historically stigmatized people suffering from mental illness (http ://strategy.mentalhealthcommission.ca /pdf/strategy-images-en.pdf).

"This is an extraordinary day for mental health in our country," Dr. David Goldbloom, chair of the commission, told reporters and assembled mental health advocates. "Thousands of Canadians have already participated in creating the strategy, and every Canadian has a role to play in making it work."

Although there is no specific price tag attached to the strategy, it calls upon Canadian governments to bump up spending on mental health to $9 \%$ of overall health spending, from a current level of $7 \%$, over the next decade. At a technical briefing May 7, commission officials projected that would require a \$4-billion investment. The strategy also calls for a $2 \%$ increase in the amount spent on mental health within education, housing and criminal justice budgets.

But the commission downplayed the required investment at its news conference. Goldbloom did not mention costs in his address, while federal Health Minister Leona Aglukkaq spoke in support of the strategy but notably, did not offer federal monies in support of the initia-

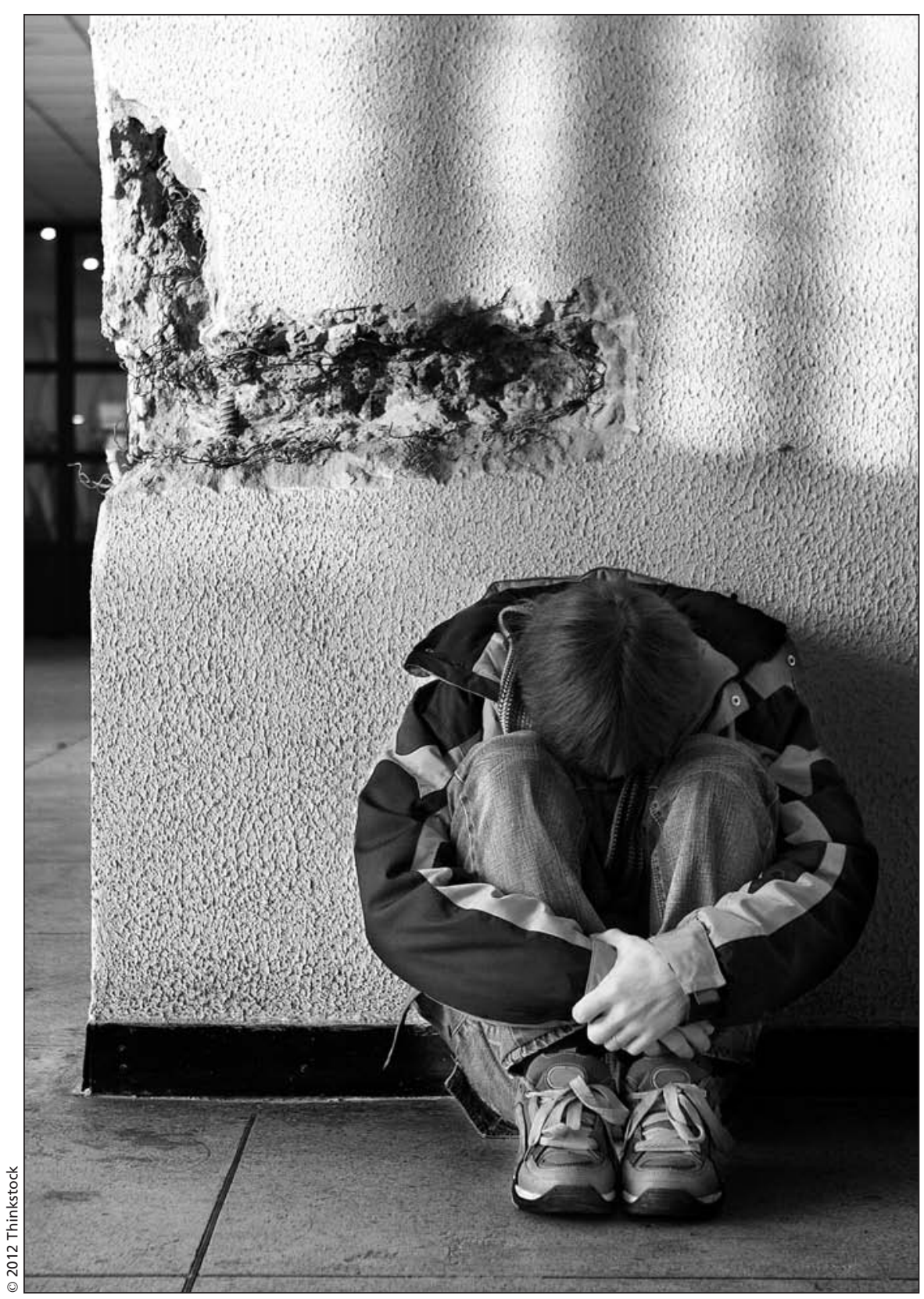

Tens of thousands of young Canadians are estimated to be homeless and at risk of mental health problems ranging from depression to highly complex disorders such as schizophrenia.

tive while indicating that Ottawa will not assume the entire financial burden.

"This strategy is a call for all of us across different levels of government, in the corporate world, in the voluntary sector; to find ways that each of us can make a difference. No single person, group or government will succeed on its own. We must promote awareness amongst all Canadians and we must make sure that all aspects of mental health are addressed at every level."

The federal government has, in the past, targeted funds at specific health ini- 
tiatives, such as the $\$ 250$ million it contributed over five years to develop a national cancer strategy. But when asked by $C M A J$ if she'll support a $2 \%$ increase in share of health spending devoted to mental health when she next meets with her provincial and territorial counterparts, Aglukkaq sidestepped the question, spoke of existing federal spending on mental health services and reiterated Ottawa's oft-repeated claim to have stabilized health transfers to the provinces.

Aglukkaq also indicated the federal government is soliciting research on mental health and homelessness but offered no details on a call for proposals.

The proposed national mental health strategy is based on the premise that people with mental illness should be provided timely access to services, treatments and supports, when and where they need them.

The level and timeliness of such services should be equivalent to that provided someone with heart disease or cancer, Goldbloom said.

Achieving that, Goldbloom added, will require contributions from all elements of society, including hospitals, schools and other institutions, businesses, communities, health care professionals and individual Canadians. "As a doctor, I wish to call on all of my colleagues in the health care community to do their part, to be part of the change."

The commission's recommendations are often extremely broad and frequently offer little in the way of specific measures that might help achieve the strategy's objectives. They range from ensuring that no child is denied access to mental health services because of a family's inability to pay for them, for example, to updating legislation to align it with the United Nations Convention on the Rights of Persons with Disabilities, and closing the gap in access to services and treatment for First Nations, Inuit and Métis people.

The strategy also calls for greater integration of mental health services with primary care. "As the role of primary health care in mental health expands, it will be important for all family physicians and other primary health care providers to work in new interdisciplinary ways and to possess core mental health competencies that are oriented to recovery and well-being. Providers will need guidelines for screening and for providing services, treatments and supports for mental health and substance use, as well as for addressing the risk of suicide. Particu- lar attention should be paid to the evolution of needs across the lifespan. People living with mental health problems and illnesses and their families must be involved in the design and evaluation of these services."

The recommendations were deliberately broad because each jurisdiction and service provider in Canada must decide how best to implement ones falling within their purview, Kirby said in an interview. "You know what you need to do, but exactly how you are going to accomplish it will vary from place to place."

Kirby plans to spearhead the marketing effort to implement the strategy in his new role as chair of Partners for Mental Health, an advocacy body associated with the commission.

In just five weeks, 25000 Canadians have already aligned themselves with the movement, Kirby says, stressing that generating public support for the initiative will be crucial to implementing the strategy. "The final step in the process of public policy change is to show decision-makers that a helluva lot of people really care about this." Laura Eggertson, Ottawa, Ont.

CMAJ 2012. DOI:10.1503/cmaj.109-4197 